\title{
Role of a Hippocampal Src-Family Kinase-Mediated Glutamatergic Mechanism in Drug Context-Induced Cocaine Seeking
}

\author{
Xiaohu Xie', Amy A Arguello', Audrey M Wells', Andrew M Reittinger' and Rita A Fuchs*,' \\ 'Department of Psychology, University of North Carolina, Chapel Hill, NC, USA
}

\begin{abstract}
Glutamatergic neurotransmission in the dorsal hippocampus $(\mathrm{DH})$ is necessary for drug context-induced reinstatement of cocaineseeking behavior in an animal model of drug relapse. Furthermore, in vitro studies suggest that the Src family of tyrosine kinases critically regulates glutamatergic cellular functions within the DH. Thus, Src-family kinases in the DH may similarly control contextual cocaineseeking behavior. To test this hypothesis, rats were trained to lever press for un-signaled cocaine infusions in a distinct context followed by extinction training in a different context. Cocaine-seeking behavior (non-reinforced active lever pressing) was then assessed in the previously cocaine-paired and extinction contexts after AP5 (N-methyl-D-aspartate glutamate (NMDA) receptor (NMDAR) antagonist; 0.25 or $2.5 \mu \mathrm{g} / 0.5 \mu \mathrm{l} /$ hemisphere), PP2 (Src-family kinase inhibitor; 6.25 or $62.5 \mathrm{ng} / 0.5 \mu \mathrm{l} /$ hemisphere), Ro25-698I (NR2B subunitcontaining NMDAR antagonist; 0.2 or $2 \mu \mathrm{g} / 0.5 \mu /$ /hemisphere), or vehicle administration into the DH. Administration of AP5, PP2, or Ro25-698 I into the DH dose-dependently impaired drug context-induced reinstatement of cocaine-seeking behavior relative to vehicle, without altering instrumental behavior in the extinction context or food-reinforced instrumental responding and general motor activity in control experiments. Cocaine-seeking behavior during the first $20 \mathrm{~min}$ of the test session in the cocaine-paired context was associated with an increase in NR2B subunit activation, and intra-DH PP2 pretreatment disrupted this relationship. Together, these findings suggest that Src-family kinase activation, NMDAR stimulation, and likely Src-family kinase-mediated NR2B subunit-containing NMDAR activation in the $\mathrm{DH}$ are necessary for incentive motivational and/or memory processes that promote contextual cocaine-seeking behavior. Neuropsychopharmacology (2013) 38, 2657-2665; doi:10.1038/npp.2013.175; published online I4 August 2013
\end{abstract}

Keywords: cocaine; context; reinstatement; dorsal hippocampus; Src-family kinases; glutamate

\section{INTRODUCTION}

Exposure to drug-associated environmental stimuli provokes relapse to drug use in cocaine users (Childress et al, 1988; Grant et al, 1996; Childress et al, 1999). Paralleling these clinical findings, exposure to a previously cocainepaired context induces cocaine-seeking behavior in the extinction-reinstatement animal model of drug relapse (Crombag et al, 2008; Fuchs et al, 2008a). Furthermore, drug context-induced reinstatement of cocaine-seeking behavior depends on glutamatergic neurotransmission, in part via the stimulation of metabotropic glutamate receptor subtype 1 (mGluR1), within the dorsal hippocampus (DH) (Xie et al, 2010).

Similar to mGluR1s, $N$-methyl-D-aspartate glutamate (NMDA) receptors (NMDARs) critically regulate environmentally induced drug-seeking behaviors. Systemic admin-

\footnotetext{
*Correspondence: Dr RA Fuchs, Department of Psychology, University of North Carolina at Chapel Hill, CB no. 3270, Davie Hall, Room I21, Chapel Hill, NC 27599-3270, USA, Tel: (919) 843 9112, Fax: (919) 962 2537, E-mail: rfuchs@unc.edu

Received 2I March 20 I3; revised II July 2013; accepted 12 July 20 I3; accepted article preview online 22 July 2013
}

istration of NMDAR antagonists inhibits the expression of cocaine-conditioned place preference and explicit cueinduced instrumental cocaine- or ethanol-seeking behaviors (Bachteler et al, 2005; Backstrom and Hyytia, 2006; Maldonado et al, 2007). These effects are mediated by NMDAR populations in multiple brain regions. Consistent with this, NMDAR antagonism in the central amygdala or the nucleus accumbens core attenuates the expression of morphine-conditioned place preference (Rezayof et al, 2007) and explicit cue-induced instrumental cocaine-seeking behavior (Backstrom and Hyytia, 2007), respectively. NMDAR antagonism in the $\mathrm{DH}$ also disrupts the expression of amphetamine-induced conditioned place preference (Sakurai et al, 2007); however, it has yet to be investigated whether the stimulation of NMDAR populations in the DH is necessary for drug context-induced reinstatement of instrumental drug-seeking behavior.

NMDAR function is critically regulated by the Src family of tyrosine kinases (Groveman et al, 2012; Salter and Kalia, 2004). Five members of the family have been identified in the mammalian brain, including Src, Fyn, Lyn, Yes, and Lck (Salter and Kalia, 2004). In cultured hippocampal neurons or brain slices, activation of Src-family kinases increases the phosphorylation of NR2B NMDAR subunits (Lu et al, 1999a; 
Stramiello and Wagner, 2008), which is required for NR2B subunit surface expression and NMDAR function (Ali and Salter, 2001; Groveman et al, 2012; Lu et al, 1999a; Salter and Kalia, 2004; Stramiello and Wagner, 2008). Conversely, pharmacological inhibition of Src-family kinases in the dorsomedial striatum decreases the phosphorylation of NR2B subunits and the expression of drugprimed alcohol-seeking behavior (Wang et al, 2010). However, the putative contributions of Src-family kinases in the $\mathrm{DH}$ to context-induced motivated behaviors, and specifically to drug context-induced cocaine-seeking behavior, have not been explored.

The present study evaluated the hypothesis that NMDARs and Src-family kinases within the DH critically regulate drug context-induced cocaine-seeking behavior. In experiments 1 and 2, we investigated the dose-dependent effects of the NMDAR antagonist, AP5, and the Src-family kinase inhibitor, PP2, in the DH on drug context-induced cocaineseeking behavior and the possible rate-altering effects of these manipulations on food-reinforced instrumental responding and general locomotor activity. In experiment 3 , we examined the effects of the behaviorally effective dose of PP2 on NR2B subunit activation in the DH in relation to drug context-induced cocaine-seeking behavior. Finally, in experiment 4 , we examined the dose-dependent effects of intra-DH administration of the selective NR2B subunitcontaining NMDAR antagonist, Ro25-6981, on drug context-induced cocaine-seeking behavior, food-reinforced instrumental responding, and locomotor activity.

\section{MATERIALS AND METHODS}

\section{Animals}

Male Sprague-Dawley rats (Charles-River, $N=64 ; 250$ $275 \mathrm{~g}$ ) were individually housed in a temperature- and humidity-controlled vivarium on a reversed light/dark cycle. Rats were maintained on $20-25 \mathrm{~g}$ of rat chow per day and ad libitum water. The housing and treatment of the rats followed the guidelines of the 'Guide for the Care and Use of Laboratory Rats' (Institute of Laboratory Animal Resources, Commission on Life Sciences 2011) and were approved by the Institutional Animal Care and Use Committee of the University of North Carolina at Chapel Hill.

\section{Food Training and Surgery}

To expedite cocaine self-administration training, rats were first trained to lever press under a fixed-ratio 1 (FR-1) schedule of food reinforcement overnight. Forty-eight hours later, they were surgically implanted with intravenous jugular catheters and 26-Ga stainless steel guide cannulae (Plastics One), aimed bilaterally at the DH (angled laterally by $15^{\circ}$; AP $-3.4 \mathrm{~mm}, \mathrm{ML}+/-3.1 \mathrm{~mm}, \mathrm{DV}-2.15 \mathrm{~mm}$ ). The food training, surgery, and post-operative care procedures have been described previously (Fuchs et al, 2007; Fuchs et al, 2008b; Xie et al, 2010).

\section{Cocaine Self-Administration and Extinction Training}

After surgical recovery, daily 2-h self-administration training sessions were conducted during the rats' dark cycle.
The operant conditioning chambers were configured to one of two distinctly different contexts (Contexts 1 and 2, described in Supplementary Materials and Methods). Active lever presses resulted in cocaine reinforcement (cocaine hydrochloride; $0.15 \mathrm{mg} / 0.05 \mathrm{ml}$ per infusion, i.v.; NIDA, Research Triangle Park, NC) under a FR-1/20 s-time-out schedule (Fuchs et al, 2007). Responses on the other (inactive) lever were recorded but had no scheduled consequences. Rats that did not reach a minimum of 10 sessions with $\geqslant 10$ cocaine infusions/session were eliminated from the experiment. The remaining rats received daily 2 -h extinction-training sessions in an alternate context (1 or 2). During extinction training, lever responses were recorded but had no scheduled consequences. Before the fourth extinction-training session, rats were adapted to the intracranial microinfusion procedure, as described previously (Fuchs et al, 2007). As active lever responses during cocaine self-administration training averaged between 50 and 75/session (see Supplementary Table S1), extinction training continued until a criterion of $\leqslant 25$ active lever responses/session on at least two consecutive days was reached. Rats that reached this criterion were used for subsequent reinstatement testing.

\section{Reinstatement Testing}

Cocaine-seeking behavior was assessed in the cocaine-paired and extinction contexts during four test sessions, using a counterbalanced experimental design, as described previously (Xie et al, 2010) and in the Supplementary Materials and Methods. Rats received bilateral vehicle or AP5 (0.25 or $2.5 \mu \mathrm{g} / 0.5 \mu \mathrm{l} / \mathrm{hemisphere} ;=7$, experiment 1 ), PP2 (6.25 or $62.5 \mathrm{ng} / 0.5 \mu \mathrm{l} /$ hemisphere; $N=8$, experiment 2 ), or Ro256981 ( 0.2 or $2 \mu \mathrm{g} / 0.5 \mu \mathrm{l} /$ hemisphere; $N=8$, experiment 4 ) microinfusions into the $\mathrm{DH}$ immediately before testing. In experiment 3, rats received bilateral vehicle or PP2 ( $62.5 \mathrm{ng} / 0.5 \mu \mathrm{l} /$ hemisphere; $N=6-9$ ) microinfusions into the $\mathrm{DH}$ and either a 1-h test session in the cocaine-paired context or exposure to the home cage, followed by euthanasia.

\section{Locomotor Activity and Food-Reinforced Instrumental Behavior}

Pharmacological manipulations may produce motor side effects that alter the expression of motivated behavior. Hence, in experiments 1,2 , and 4 , at least $72 \mathrm{~h}$ after the last reinstatement test session, we examined the effects of AP5, PP2, and Ro25-6981 on general locomotor activity and on food-reinforced instrumental motor performance in different subsets of rats ( $N=7-8$ /group), as described previously by Xie et al (2010) and in Supplementary Materials and Methods.

\section{Histology and Western Blotting}

In experiments 1,2 , and 4 , rats were overdosed using ketamine and xylazine $(66.6$ and $1.3 \mathrm{mg} / \mathrm{kg}$ intravenous or 133.2 and $2.6 \mathrm{mg} / \mathrm{kg}$ intraperitoneal, depending on catheter patency). The brains were dissected out, post-fixed with $10 \%$ formaldehyde, sectioned at $75 \mu \mathrm{m}$, and stained with cresyl violet (Kodak, Rochester, NY). The most ventral 
point of each cannula track was mapped onto schematics from the rat brain atlas (Paxinos and Watson 1997).

In experiment 3, rats were euthanized via rapid decapitation immediately after the 1 -h reinstatement test session or home cage exposure. Brains were dissected out, flash frozen in isopentane at $-20{ }^{\circ} \mathrm{C}$, and stored at $-80^{\circ} \mathrm{C}$. $\mathrm{DH}$ punches were taken with $19-\mathrm{Ga}$ neuropunches (Fine Science Tools) and $40-\mu \mathrm{m}$ coronal tissue sections were also collected to verify cannula placement. Punched tissue was stored at $-80{ }^{\circ} \mathrm{C}$ in lysis buffer, containing $10 \mathrm{mM}$ HEPES, $1 \%$ SDS, $11 \%$ sucrose, and $1 \mathrm{x}$ protease and phosphatase inhibitor cocktails (Sigma-Aldrich, St Louis, MO). Tissue samples were homogenized manually and boiled in a dry heat block at $100{ }^{\circ} \mathrm{C}$ for $10 \mathrm{~min}$. The protein concentration of samples was determined using the Biorad DC Protein Assay kit. Proteins were separated on $7.5 \%$ Tris- $\mathrm{HCl}$ polyacrylamide gel and transferred to a polyvinylidene difluoride membrane (Millipore, Billerica, MA) for $1 \mathrm{~h}$ at $100 \mathrm{~V}$. Membranes were then blocked in $5 \%$ milk for $1 \mathrm{~h}$, and incubated with rabbit anti-phospho-NMDA NR2B polyclonal antibody (pTyr1472, 1:1000, Sigma-Aldrich) overnight $(16-20 \mathrm{~h})$ at $4{ }^{\circ} \mathrm{C}$. Membranes were incubated in donkey anti-rabbit polyclonal secondary antibody (1:10000, GE Healthcare, Piscataway, NJ) conjugated to horseradish peroxidase (HRP) for $1 \mathrm{~h}$ followed by development with an enhanced chemiluminescence system (Pierce Biotech, Rockford, IL). Membranes were washed with stripping buffer $(62.5 \mathrm{mM}$ Tris- $\mathrm{HCl}$ at $\mathrm{pH}$ 6.7, 2\% SDS, $100 \mathrm{mM}$ beta-mercaptoethanol) to permit re-probing with antibodies to total NR2B (1:1000, Millipore) and actin-HRP (ie, loading control; 1:50000, Santa Cruz Biotechnology, Santa Cruz, CA). pNR2B, total NR2B, and actin protein levels were quantified by densitometry, using NIH Image J software. pNR2B levels were normalized to total NR2B levels, and no difference was observed in total NR2B levels, when normalized to actin. Subsequent discussion of NR2B activation refers to normalized pNR2B/total NR2B levels.

\section{Data Analysis}

Data were analyzed with univariate correlation and mixedfactorial analyses of variance (ANOVAs), where appropriate, as described in Supplementary Material and Methods. Significant ANOVA main and interaction effects were further investigated using Tukey post hoc tests, when appropriate. Alpha $(\alpha)$ was set at 0.05 .

\section{RESULTS}

\section{Histology}

Schematics illustrating cannula placement and photomicrographs showing a representative cannula tract and $\mathrm{DH}$ micropunch are included in Figure 1. The most ventral point of the infusion cannula tracks was located within the Cornus Ammonis 1/3 (CA1/CA3) subregions of the DH bilaterally in all rats in experiments 1 (Figure 1a), 2 (Figure 1b), and 4 (Figure 1d). Furthermore, high power microscopy did not reveal any evidence of abnormal tissue damage (ie, extensive cell loss or gliosis) at the infusion site. $\mathrm{DH}$ micropunches were collected bilaterally around the a
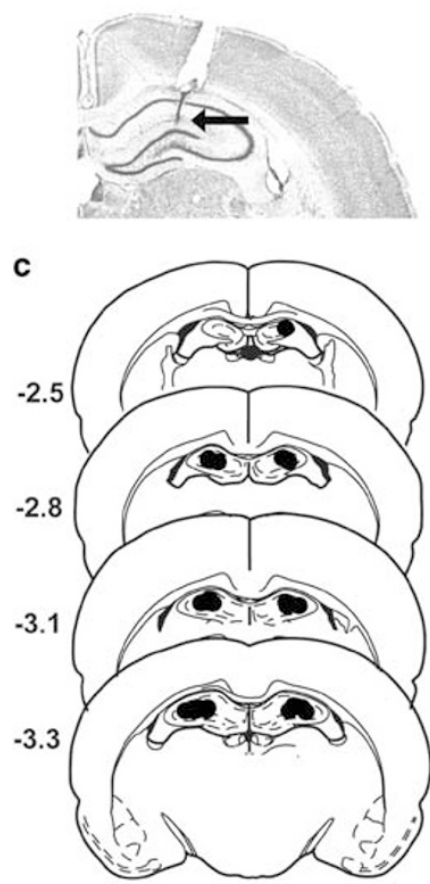

e

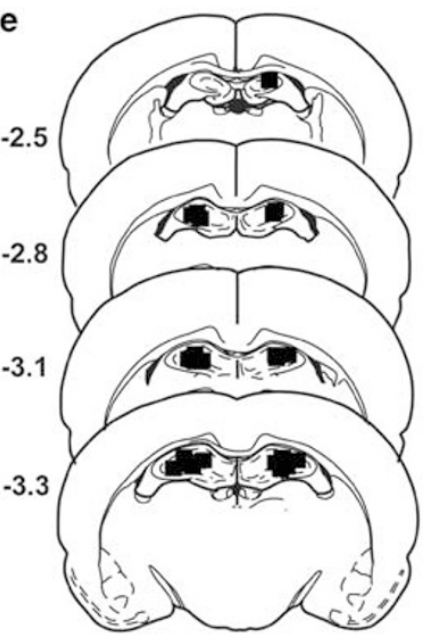

b

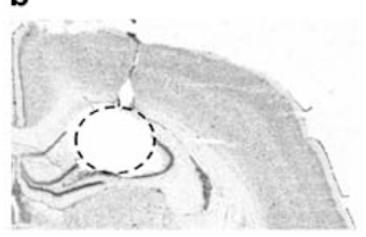

d

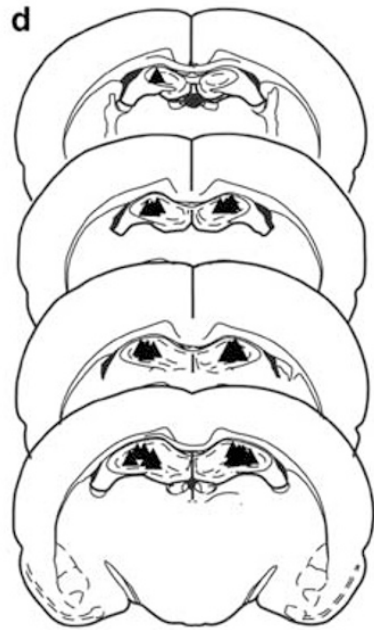

f

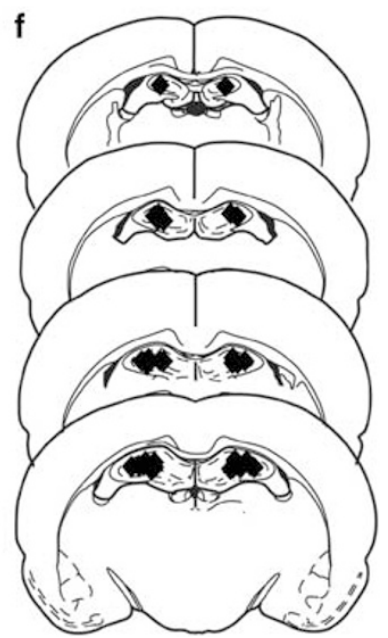

Figure I Schematic and photographic representation of injection cannula placements within the dorsal hippocampus (DH). On the photomicrographs of cresyl violet-stained sections, the arrow and segmented circle identify a representative cannula placement (a) and sampling area for western blot analysis (b), respectively. On the schematics adapted from Paxinos and Watson (1997), filled circles (c), filled triangles (d), filled squares (e), and filled diamonds ( $f$ represent the most ventral point of the cannula tracks for rats in experiments I, 2, 3, and 4, respectively. Numbers indicate distance from bregma in millimeters.

infusion site in all rats in experiment 3 (Figure 1c). The sample sizes are reported in the figure captions.

\section{Cocaine Self-Administration and Extinction}

There were no pre-existing differences between the experimental groups in cocaine intake, active or inactive lever responding during cocaine self-administration training or extinction training, or in the number of days required to reach the extinction criterion. The corresponding 
descriptive statistics are provided in Supplementary Results and Supplementary Table S1.

\section{Reinstatement}

In each experiment, following vehicle administration into the $\mathrm{DH}$, active and inactive lever responding was independent of testing context order, treatment order, and treatment on the other test day (ie, dose of AP5, PP2, or Ro25-6981). Therefore, data were collapsed across these variables to form a single-vehicle condition. Inactive lever responding was low in all experiments and was not altered by the pharmacological manipulations (all treatment main and interaction effects, Fs $<1.64, p>0.21$; Supplementary Figure S2).

\section{Effects of Intra-DH AP5 Treatment on Drug Context-Induced Cocaine-Seeking and Motor Behaviors}

Intra-DH AP5 treatment attenuated active lever responding as a function of testing context and dose (Figure 2a). Following pretreatment with vehicle or the $0.25 \mu \mathrm{g}$ dose of AP5 into the DH, exposure to the cocaine-paired context increased active lever responding relative to responding in the extinction context (all treatment main and interaction effects, $\mathrm{F}_{(1-2,25)}=4.16-33.98, p=0.0001-0.03$, Tukey test, $p<0.05)$. The $0.25 \mu \mathrm{g}$ dose of AP5 failed to alter active lever responding in either context relative to vehicle. Conversely, the $2.5 \mu \mathrm{g}$ dose of AP5 decreased active lever responding in the cocaine-paired context (Tukey test, $p<0.05$ ), without altering responding in the extinction context, relative to vehicle.

During the locomotor activity test session, the number of photobeam breaks gradually decreased (time main effect, $\mathrm{F}_{(2,12)}=21.32, p=0.0001 ; 20$-min interval $1>2-3$, Tukey test, $p<0.05)$. Furthermore, the behaviorally effective, $2.5 \mu \mathrm{g}$ dose of AP5 did not alter the number of photobeam breaks relative to vehicle (treatment main and interaction effects, $\mathrm{F}_{(1-2,6-12)}=0.35-2.05, p=0.17-0.58$; Figure $2 \mathrm{~b}$ ).

Food reinforcement elicited greater responding on the active lever than on the inactive lever (lever main effect, $\left.\mathrm{F}_{(1,6)}=31.76, p=0.001\right)$. Furthermore, $2.5 \mu \mathrm{g}$ dose of AP5 did not alter food-reinforced active or inactive lever responding, relative to vehicle (all treatment main and interaction effects, $\mathrm{F}_{(1,6)}=0.49-0.51, p=0.50-0.51$; Figure 2c).

\section{Effects of Intra-DH PP2 Treatment on Drug Context-Induced Cocaine-Seeking and Motor Behaviors}

Intra-DH PP2 treatment attenuated active lever responding as a function of testing context and dose (Figure 3a). Following pretreatment with vehicle or the $6.25 \mathrm{ng}$ dose of PP2, exposure to the cocaine-paired context increased active lever responding relative to responding in the extinction context (all treatment main and interaction effects, $\mathrm{F}_{(1-2,29)}=4.13-43.73, p=0.0001-0.03$, Tukey test, $p<0.05)$. The $6.25 \mathrm{ng}$ dose of PP2 failed to alter active lever responding in either context relative to vehicle. In contrast, the $62.5 \mathrm{ng}$ dose decreased active lever responding in the cocaine-paired context (Tukey test, $p<0.05$ ), without altering active lever responding in the extinction context, relative to vehicle.

During the locomotor activity test session, the number of photobeam breaks gradually decreased (time main effect, $\mathrm{F}_{(2,14)}=39.14, p=0.0001 ; 20$-min interval $1>2-3$, Tukey test, $p<0.05$; Figure $3 \mathrm{~b}$ ). Furthermore, the behaviorally effective, $62.5 \mathrm{ng}$ dose of PP2 did not alter the number of photobeam breaks relative to vehicle (treatment main and interaction effects, $\left.\mathrm{F}_{(1-2,7-14)}=0.35-0.86, p=0.38-0.71\right)$.

Food reinforcement elicited robust responding on the active lever (lever main effect, $\mathrm{F}_{(1,7)}=158.60, p=0.0001$; Figure $3 \mathrm{c}$ ). However, the $62.5 \mathrm{ng}$ dose of PP2 did not alter food-reinforced active or inactive lever responding, relative to vehicle (all treatment main and interaction effects, $\mathrm{F}_{(1 \text {, }}$ 7) $=0.003-0.016, p=0.90-0.96)$.

\section{Effects of Intra-DH PP2 Treatment on NR2B Activation and Drug Context-Induced Cocaine Seeking}

Replicating experiment 2, intra-DH administration of the $62.5 \mathrm{ng}$ dose of PP2 altered active lever responding as a function of context and time (all treatment main and interaction effects, $\mathrm{F}_{(1,16)}=18.21-45.72, p=0.0001-0.001$; Supplementary Figure S2). Specifically, following bilateral administration of vehicle in the $\mathrm{DH}$, robust active lever responding occurred during the first $20 \mathrm{~min}$, and it declined during the test session in the cocaine-paired
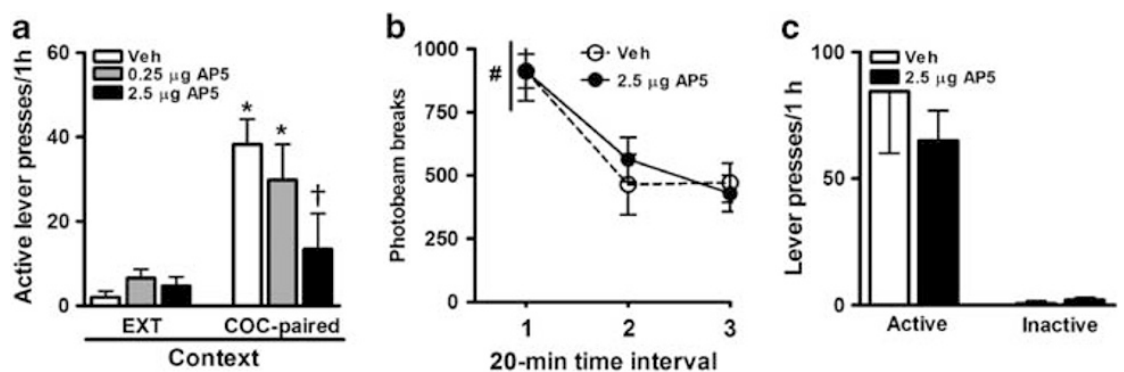

Figure 2 Effects of bilateral AP5 pretreatment in the dorsal hippocampus (DH) on non-reinforced active lever responses $(a: m e a n / I ~ h+S E M ; ~ N=7-\mid 4 /$ dose) during testing in the extinction (EXT) and previously cocaine-paired contexts (COC), on locomotor activity in a novel context (b: mean photobeam breaks/l h $+\mathrm{SEM} ; N=7 /$ dose), and on food-reinforced instrumental behavior in a neutral context (c: mean active and inactive lever presses/I h + SEM; $N=7 /$ dose). Asterisks represent significant difference relative to responding in the extinction context (analysis of variance (ANOVA) context simple main effect, Tukey test, $p<0.05$ ). Dagger represents significant difference relative to vehicle treatment (ANOVA treatment simple main effect, Tukey test, $p<0.05$ ). Pound sign represents significant difference relative to all other time points (ANOVA time simple main effect, Tukey test, $p<0.05$ ). 

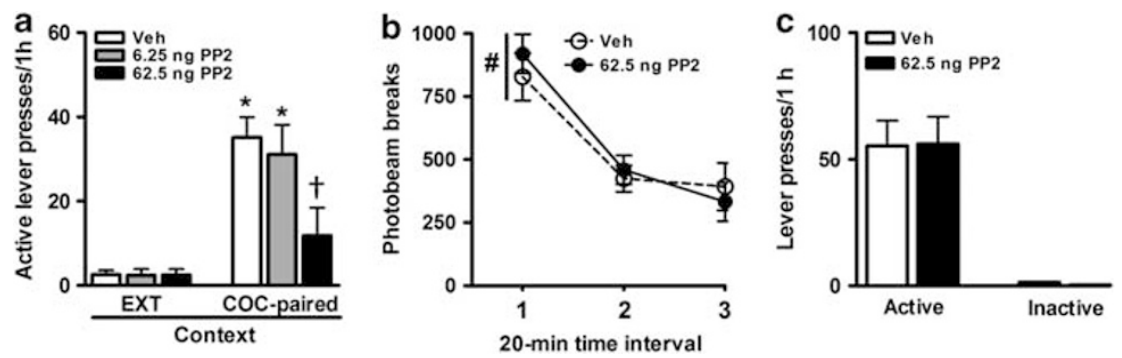

Figure 3 Effects of bilateral PP2 pretreatment in the dorsal hippocampus $(\mathrm{DH})$ on non-reinforced active lever responses $(\mathrm{a}$ : $\mathrm{mean} / \mathrm{I} \mathrm{h}+\mathrm{SEM}$; $\mathrm{N}=8-\mathrm{I}$ / dose) during testing in the extinction (EXT) and previously cocaine-paired contexts (COC), on locomotor activity in a novel context (b: mean photobeam breaks/I h + SEM; $N=8 /$ dose), and on food-reinforced instrumental behavior in a neutral context (c: mean active and inactive lever presses/l $\mathrm{h}+\mathrm{SEM}$; $\mathrm{N}=8 /$ dose). Asterisks represent significant difference relative to responding in the extinction context (analysis of variance (ANOVA) context simple main effect, Tukey test, $p<0.05$ ). Dagger represents significant difference relative to vehicle treatment (ANOVA treatment simple main effect, Tukey test, $p<0.05$ ). Pound sign represents significant difference relative to all other time points (ANOVA time simple main effect, Tukey test, $p<0.05$ ).
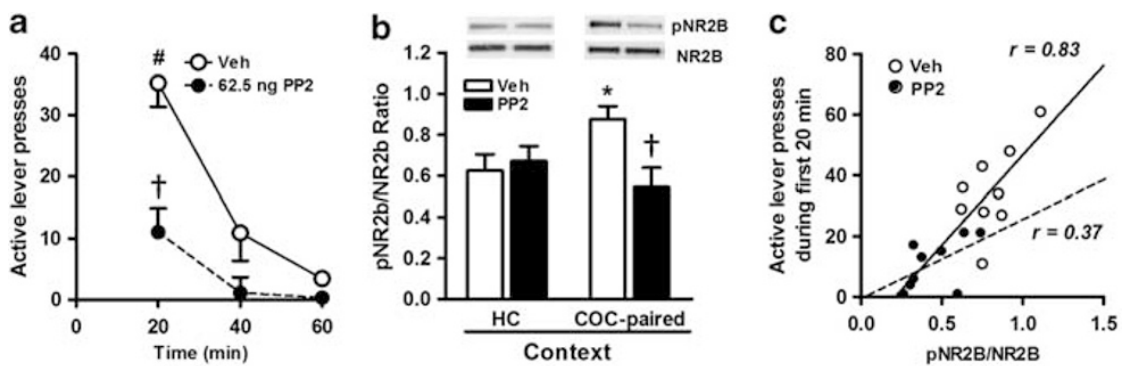

Figure 4 Effects of bilateral PP2 pretreatments in the dorsal hippocampus $(\mathrm{DH})$ on non-reinforced active lever responses (a: mean/20 min + SEM; $N=9 /$ dose) during a 60-min test in the previously cocaine-paired context (COC), on NR2B N-methyl-D-aspartate glutamate (NMDA) subunit activation in the DH following testing in the cocaine-paired context or home cage $(\mathrm{HC})$ exposure (b: mean ratio + SEM; $N=9 /$ dose), and on the relationship between the level of NR2B NMDA subunit activation and active lever responding during the first $20 \mathrm{~min}$ of testing in the cocaine-paired context $(c: N=9)$. Pound sign represents significant difference relative to all other time points (analysis of variance (ANOVA) time simple main effect, Tukey test, $p<0.05$ ). Daggers represent significant difference relative to vehicle treatment (ANOVA treatment simple main effect, Tukey test, $p<0.05$ ). Asterisk represents significant difference relative to $\mathrm{HC}$ control (Tukey test, $p<0.05$ ). The $r$ values refer to Pearson's correlational coefficients (vehicle, $p=0.005 ;$ PP2, $p=0.32$ ).

context (Tukey test, $p<0.01,20$-min interval $1>2-3$; Figure 4a). Bilateral administration of $62.5 \mathrm{ng}$ dose of PP2 into the $\mathrm{DH}$ reduced active lever responding during the first $20 \mathrm{~min}$ in the cocaine-paired context, relative to vehicle (all treatment main and interaction effects, $\mathrm{F}_{(1-2,16-32)}=9.63-$ 41.90, $p=0.0001-0.001$, Tukey test, $p<0.01$; Figure $4 \mathrm{a}$ ).

Western blot analyses of NR2B activation were conducted on tissues collected immediately after this 1-h test session or home cage exposure (ie, 60-65 min following PP2 administration). In the vehicle-treated rats, NR2B activation in the $\mathrm{DH}$ was greater following testing in the cocaine-paired context, relative to home cage exposure (treatment main and interaction effects, $\mathrm{F}_{(1,31)}=4.47-$ 8.33, $p=0.008-0.044$, Tukey test, $p<0.05$; context main effect, $F_{(1,31)}=5.05, p=0.033$; Figure $\left.4 \mathrm{~b}\right)$. Furthermore, PP2 pretreatment attenuated the increase in NR2B activation following testing in the cocaine-paired context (Tukey test, $p<0.05$ ), but did not alter NR2B activation following home cage exposure (Figure 4b). For vehicletreated rats, there was a positive correlation between NR2B activation and active lever responding during the first $20 \mathrm{~min}$ the test session (Pearson's $r=0.83, p=0.005$; Figure 4c), and PP2 eliminated this correlation (Pearson's $r=0.37, p=0.32$; Figure $4 \mathrm{c}$ ). Notably, correlations could not be detected between NR2B activation and (1) active lever responding during the second and third 20-min intervals of the test session, likely due to low variability in responding after behavioral extinction (Pearson's $r=0.30-0.49, p=0.09-0.79$; data not shown), and (2) cocaine history (ie, total drug intake during self-administration training, Pearson's $r=0.21, p=0.46$; data not shown).

\section{Effects of Intra-DH Ro 25-6981 Treatment on Drug Context-Induced Cocaine-Seeking and Motor Behaviors}

Intra-DH Ro25-6981 treatment attenuated active lever responding as a function of testing context and dose (Figure 5a). Following pretreatment with vehicle or the $0.2 \mu \mathrm{g}$ dose of Ro25-6981, exposure to the cocaine-paired context increased active lever responding relative to responding in the extinction context (all treatment main and interaction effects, $\mathrm{F}_{(1-2,29)}=4.08-72.74, p=0.0001-$ 0.02 , Tukey test, $p<0.05)$. The $0.2 \mu \mathrm{g}$ dose of Ro25-6981 failed to alter active lever responding in either context relative to vehicle. In contrast, the $2.0 \mu \mathrm{g}$ dose decreased active lever responding in the cocaine-paired context (Tukey test, $p<0.05$ ), without altering active lever responding in the extinction context, relative to vehicle.

During the locomotor activity test session, the number of photobeam breaks gradually decreased (time main effect, $\mathrm{F}_{(2,14)}=66.18, p=0.0001 ; 20$-min interval $1>2-3$, Tukey test, $p<0.05)$. Furthermore, the behaviorally effective, $2.0 \mu \mathrm{g}$ dose of Ro25-6981 did not alter the number of photobeam breaks relative to vehicle (treatment main and interaction effect, $\mathrm{F}_{(1-2,7-14)}=0.20-1.17, p=0.34-0.67$; Figure 5b). 

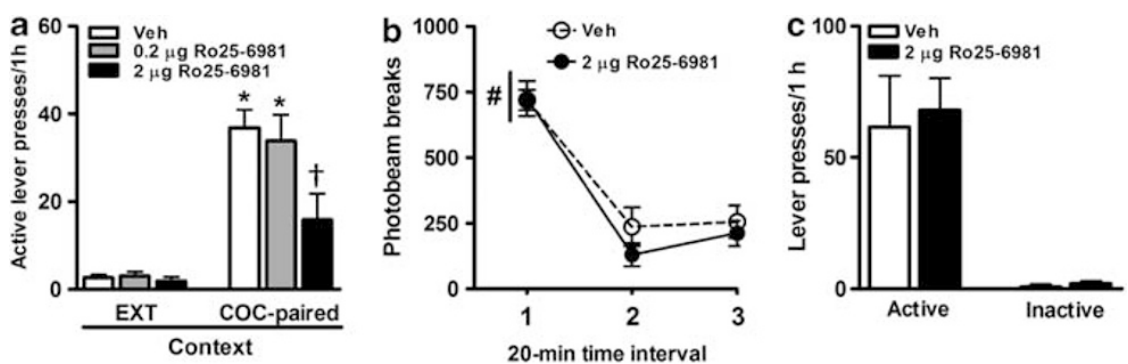

Figure 5 Effects of bilateral Ro25-698I pretreatment in the dorsal hippocampus (DH) on non-reinforced active lever responses (a: mean/l h + SEM; $N=8-16 /$ dose) during testing in the extinction (EXT) and previously cocaine-paired contexts (COC), on locomotor activity in a novel context (b: mean photobeam breaks/l h+SEM; N=8/dose), and on food-reinforced instrumental behavior (c: mean active and inactive lever presses/l h + SEM; $N=8 /$ dose). Asterisks represent significant difference relative to responding in the extinction context (analysis of variance (ANOVA) context simple main effect, Tukey test, $p<0.05$ ). Dagger represents significant difference relative to vehicle treatment (ANOVA treatment simple main effect, Tukey test, $p<0.05$ ). Pound sign represents significant difference relative to all other time points (ANOVA time simple main effect, Tukey test, $p<0.05$ ).

Food reinforcement elicited greater responding on the active lever than on the inactive lever (lever main effect, $\mathrm{F}_{(1,7)}=42.11$, $p=0.0001)$. Furthermore, the $2.0 \mu \mathrm{g}$ dose of Ro25-6981 did not alter food-reinforced active or inactive lever responding, relative to vehicle (all treatment main and interaction effects, $\mathrm{F}_{(1,7)}=0.04-0.09, p=0.77-0.84$; Figure $5 \mathrm{c}$ ).

\section{DISCUSSION}

This study evaluated the contribution of Src-family kinases, NMDARs, and specifically NR2B subunit-containing NMDARs, in the expression of drug context-induced cocaine-seeking behavior. PP2-induced Src-family kinase inhibition or AP5-induced NMDAR antagonism in the DH dose-dependently attenuated this behavior relative to vehicle. NR2B NMDAR subunit activation in the DH increased following the test of cocaine-seeking behavior in the previously cocaine-paired context, relative to home cage exposure. The behaviorally effective dose of PP2 selectively decreased NR2B activation in the $\mathrm{DH}$, which was associated with reduction in drug context-induced cocaine-seeking behavior. Similarly, Ro25-6981-induced selective antagonism of NR2B subunit-containing NMDARs in the DH dose-dependently attenuated drug context-induced cocaineseeking behavior relative to vehicle. These manipulations did not produce non-specific performance deficits, as they did not alter instrumental performance in the extinction context, general locomotor activity, or food-reinforced instrumental behavior. Furthermore, the manipulations were probably selective to the anterior CA1/CA3 regions of the $\mathrm{DH}$, as we have previously shown that global neuronal inactivation of the overlying cortex or of the adjacent dentate gyrus or posterior CA1/CA3 regions of the DH fails to alter drug context-induced cocaine seeking (Fuchs et al, 2005; Lasseter et al, 2010). Together, these findings suggest that activation of Src-family kinases, stimulation of NMDAR, and likely Src-family kinasemediated NR2B-containing NMDAR activation in the DH are necessary for drug context-induced cocaine-seeking behavior.

The present study significantly extends upon our previous finding that mGluR1 stimulation in the $\mathrm{DH}$ is necessary for drug context-induced cocaine-seeking behavior (Xie et al, 2010) by demonstrating the critical role of NMDAR in this phenomenon. Furthermore, in the present study, NMDAR antagonism and selective NR2B inhibition had similar behavioral effects, suggesting that NR2B subunit-containing NMDARs have a critical role in drug context-induced cocaine seeking. However, these pharmacological manipulations were not aimed at a particular subregion of the DH (eg, CA1-3, dentate gyrus). NMDARs are mostly postsynaptic in the hippocampus (Nyiri et al, 2003; Takumi et al, 1999), and have a greater expression of NR2B subunits than other NMDA subunits (ie, NR2A) in the CA1 subregion, but not in the CA3 subregion or the dentate gyrus (Coultrap et al, 2005; Pandis et al, 2006). Also, within the CA1 subregion, NMDAR subunit composition and density vary across cell types (Angulo et al, 2004; Nyiri et al, 2003; Serrano et al, 2006; Serrano et al, 2008; Siegel et al, 1994; Szabadits et al, 2011; Todd et al, 2006; Xue et al, 2011). Thus, given the functional heterogeneity of hippocampal NMDAR populations (Kesner, 2007; Lee et al, 2003), future studies will be necessary to dissect the role of distinct NR2B subunitcontaining NMDAR subpopulations within the DH in drug context-induced cocaine-seeking behavior.

Although NMDAR stimulation or Src-family kinase activity in the DH was not necessary for food-reinforced lever pressing behavior in the present study, it is unclear whether NMDARs or Src-family kinases in the DH contribute to contextual natural reward-seeking behavior per se. When applied to a food reinforcer, our training protocol is not sufficient to elicit contextual food-seeking behavior (Xie et al, 2010). This may be due to overshadowing by highly predictive, food-related visual, olfactory, and gustatory stimuli during food self-administration training, which diminishes the salience and associative value of the food-predictive context (Xie et al, 2010). Given that food-related sensory stimuli could not be eliminated, a direct comparison of the role of NMDARs or Src-family kinases in contextual drug-seeking $v s$ natural rewardseeking behaviors was not feasible in the present study.

NMDARs in the DH have been implicated in various memory processes. For instance, NMDAR stimulation is necessary for the retrieval or expression of spatial, inhibitory avoidance, and trace fear memory (Corcoran et al, 2011; Matus-Amat et al, 2007; Melik et al, 2006; Quinn et al, 2005; Rodrigues et al, 2001), but not contextual fear memory (Fellini et al, 2009; Jamali-Raeufy et al, 2011; Quinn et al, 2005; 
Yoshihara and Ichitani, 2004). Adding to this literature, the present findings suggest that NMDARs, specifically NR2B subunit-containing NMDARs, in the $\mathrm{DH}$ are required for the recall or utilization of context-response-cocaine associative memories and/or for motivational processes that underlie contextual control over drug-seeking behavior (Fuchs et al, 2008a). Conversely, NMDAR stimulation in the $\mathrm{DH}$ is not critical for the retrieval or utilization of extinction memories as NMDAR antagonism did not increase lever responding in the extinction context.

Functional interactions between Src-family kinases and NMDARs are well documented. Src-family kinases can phosphorylate NR2B subunits at tyrosine residue 1472, which is critical for NR2B subunit-containing NMDAR surface expression and functional potentiation (Ali and Salter, 2001; Groveman et al, 2012; Lu et al, 1999a; Salter, 1998; Salter and Kalia, 2004; Sinai et al, 2010; Stramiello and Wagner, 2008). The present study revealed that NR2B phosphorylation at Y1472 in the DH increased following testing in the cocaine-paired context, relative to home cage exposure. Although this increase was independent of cocaine history, it was positively correlated with the magnitude of cocaine-seeking behavior during the first 20 min of the test session. PP2 treatment in the DH disrupted this relationship and reduced NR2B activation following testing in the cocaine-paired context to a level seen following home cage exposure, without altering NR2B activation following home cage exposure. These findings suggest that Src-family kinase-mediated NR2B activation is critical for drug context-induced cocaine-seeking behavior. However, future studies will need to explore whether DH NR2B activation is sufficient to increase drug contextinduced cocaine-seeking behavior or goal-directed behavior in general.

PP2 strongly inhibits several members of the Src tyrosine kinase family, including Src, Lck, Fyn, and Hck in vitro $\left(\mathrm{IC}_{50}=4-170 \mathrm{nM}\right.$; Bain et al, 2003; Hanke et al, 1996; Lawrence and Niu, 1998). In vivo studies demonstrate that Fyn activation is necessary for a number of aversive conditioned behaviors as well as alcohol-conditioned place preference, alcohol self-administration, and drug-primed reinstatement of alcohol-seeking behavior, in a brain region-specific manner (Isosaka et al, 2008; Kojima et al, 2005; Schafe et al, 1996; Wang et al, 2007; Wang et al, 2010; but see Yaka et al, 2003). Within the DH, Fyn activation is required for contextual fear conditioning (Isosaka et al, 2008). Fyn knockout mice exhibit deficiency in hippocampal long-term potentiation (LTP) induction and spatial learning (Grant et al, 1992), while overexpression of constitutively active mutant Fyn results in enhanced excitatory postsynaptic potentials in response to afferent stimulation and reduced hippocampal LTP induction threshold (Lu et al, 1999b). Given that functional heterogeneity may exist across members of the Src tyrosine kinase family, future studies will be necessary in order to identify whether Fyn or other Src-family kinases exert dominant control over drug context-induced cocaine-seeking behavior.

Various neurochemical mechanisms, including glutamate or dopamine receptor stimulation, may trigger Src-family kinase-mediated NR2B activation in the DH. For example, mGluR1 stimulation activates Src-family kinases (Heuss et al, 1999) and potentiates NMDAR current in hippocampal pyramidal cells (Benquet et al, 2002). Dopamine D1-like receptor stimulation in the hippocampus also enhances the Src-family kinase-mediated phosphorylation of NR2B subunits and potentiates D1-like receptor-mediated LTP (Stramiello and Wagner, 2008). Furthermore, mGluR1 or D1-like receptor stimulation in the $\mathrm{DH}$ is necessary for drug context-induced cocaine-seeking behavior (Xie et al, 2010; Xie and Fuchs, unpublished data). However, distinct pools of Src-family kinase activated by different intracellular signaling pathways may have different functions. Therefore, it will be important to identify the upstream activators of Src-family kinases in the $\mathrm{DH}$ that contribute to drug context-induced cocaine-seeking behavior per se.

Importantly, plasticity in Src-family kinase function may fundamentally contribute to the development of compulsive cocaine-seeking and -taking behaviors. Consistent with this, acute cocaine exposure increases Src-family kinase activation in the ventral tegmental area (Schumann et al, 2009). Furthermore, chronic alcohol exposure produces longlasting Fyn activation in the dorsomedial striatum, which is critical for alcohol self-administration and drug-primed alcohol-seeking behavior (Wang et al, 2010). Similar plasticity in DH Src-family kinase physiology has yet to be demonstrated, but understanding putative, drug-induced, or experience-based neuroplasticity in Src-family kinase activity within the $\mathrm{DH}$ and other limbic brain regions may aid in the development of effective treatments for drug relapse prevention.

\section{FUNDING AND DISCLOSURE}

The authors declare no conflict of interest. This work was supported by National Institute on Drug Abuse R01s DA017673 and DA025646, and F31s DA028051 and DA034391.

\section{ACKNOWLEDGEMENTS}

The authors thank Sierra Stringfield, Megan Blanton and Matthew Hodges for excellent technical assistance. The authors also thank Dr Jacqueline McGinty for insightful comments on an earlier version of the manuscript.

\section{REFERENCES}

Ali DW, Salter MW (2001). NMDA receptor regulation by Src kinase signalling in excitatory synaptic transmission and plasticity. Curr Opin Neurobiol 11: 336-342.

Angulo MC, Kozlov AS, Charpak S, Audinat E (2004). Glutamate released from glial cells synchronizes neuronal activity in the hippocampus. J Neurosci 24: 6920-6927.

Bachteler D, Economidou D, Danysz W, Ciccocioppo R, Spanagel $R$ (2005). The effects of acamprosate and neramexane on cueinduced reinstatement of ethanol-seeking behavior in rat. Neuropsychopharmacology 30: 1104-1110.

Backstrom P, Hyytia P (2006). Ionotropic and metabotropic glutamate receptor antagonism attenuates cue-induced cocaine seeking. Neuropsychopharmacology 31: 778-786.

Backstrom P, Hyytia P (2007). Involvement of AMPA/kainate, NMDA, and mGlu5 receptors in the nucleus accumbens core in 
cue-induced reinstatement of cocaine seeking in rats. Psychopharmacology 192: 571-580.

Bain J, McLauchlan H, Elliott M, Cohen P (2003). The specificities of protein kinase inhibitors: an update. Biochem J 371(Pt 1): 199-204.

Benquet P, Gee CE, Gerber U (2002). Two distinct signaling pathways upregulate NMDA receptor responses via two distinct metabotropic glutamate receptor subtypes. J Neurosci 22: 9679-9686.

Childress AR, McLellan AT, Ehrman R, O’Brien CP (1988). Classically conditioned responses in opioid and cocaine dependence: a role in relapse? NIDA Res Monogr 84: 25-43.

Childress AR, Mozley PD, McElgin W, Fitzgerald J, Reivich M, O’Brien CP (1999). Limbic activation during cue-induced cocaine craving. Am J Psychiatry 156: 11-18.

Corcoran KA, Donnan MD, Tronson NC, Guzman YF, Gao C, Jovasevic $\mathrm{V}$ et al (2011). NMDA receptors in retrosplenial cortex are necessary for retrieval of recent and remote context fear memory. J Neurosci 31: 11655-11659.

Coultrap SJ, Nixon KM, Alvestad RM, Valenzuela CF, Browning MD (2005). Differential expression of NMDA receptor subunits and splice variants among the CA1, CA3 and dentate gyrus of the adult rat. Brain Res Mol Brain Res 135: 104-111.

Crombag HS, Bossert JM, Koya E, Shaham Y (2008). Contextinduced relapse to drug seeking: a review. Philos Trans $R$ Soc Lond B Biol Sci 363: 3233-3243.

Fellini L, Florian C, Courtey J, Roullet P (2009). Pharmacological intervention of hippocampal CA3 NMDA receptors impairs acquisition and long-term memory retrieval of spatial pattern completion task. Learn Mem 16: 387-394.

Fuchs RA, Eaddy JL, Su ZI, Bell GH (2007). Interactions of the basolateral amygdala with the dorsal hippocampus and dorsomedial prefrontal cortex regulate drug context-induced reinstatement of cocaine-seeking in rats. Eur J Neurosci 26: 487-498.

Fuchs RA, Evans KA, Ledford CC, Parker MP, Case JM, Mehta RH et al (2005). The role of the dorsomedial prefrontal cortex, basolateral amygdala, and dorsal hippocampus in contextual reinstatement of cocaine seeking in rats. Neuropsychopharmacology 30: 296-309.

Fuchs RA, Lasseter HC, Ramirez DR, Xie X (2008a). Relapse to drug seeking following prolonged abstinence: the role of environmental stimuli. Drug Discov Today Dis Models 5: 251-258.

Fuchs RA, Ramirez DR, Bell GH (2008b). Nucleus accumbens shell and core involvement in drug context-induced reinstatement of cocaine seeking in rats. Psychopharmacology 200: 545-556.

Grant S, London ED, Newlin DB, Villemagne VL, Liu X, Contoreggi C et al (1996). Activation of memory circuits during cue-elicited cocaine craving. Proc Natl Acad Sci USA 93: 12040-12045.

Grant SG, O'Dell TJ, Karl KA, Stein PL, Soriano P, Kandel ER (1992). Impaired long-term potentiation, spatial learning, and hippocampal development in fyn mutant mice. Science 258: 1903-1910.

Groveman BR, Feng S, Fang XQ, Pflueger M, Lin SX, Bienkiewicz EA et al (2012). The regulation of $\mathrm{N}$-methyl-D-aspartate receptors by Src kinase. FEBS J 279: 20-28.

Hanke JH, Gardner JP, Dow RL, Changelian PS, Brissette WH, Weringer EJ et al (1996). Discovery of a novel, potent, and Src family-selective tyrosine kinase inhibitor. Study of Lck- and FynT-dependent T cell activation. J Biol Chem 271: 695-701.

Heuss C, Scanziani M, Gahwiler BH, Gerber U (1999). G-proteinindependent signaling mediated by metabotropic glutamate receptors. Nat Neurosci 2: 1070-1077.

Isosaka T, Hattori K, Kida S, Kohno T, Nakazawa T, Yamamoto T et al (2008). Activation of Fyn tyrosine kinase in the mouse dorsal hippocampus is essential for contextual fear conditioning. Eur J Neurosci 28: 973-981.
Jamali-Raeufy N, Nasehi M, Zarrindast MR (2011). Influence of N-methyl D-aspartate receptor mechanism on WIN55,212-2induced amnesia in rat dorsal hippocampus. Behav Pharmacol 22: 645-654.

Kesner RP (2007). Behavioral functions of the CA3 subregion of the hippocampus. Learn Mem 14: 771-781.

Kojima N, Sakamoto T, Endo S, Niki H (2005). Impairment of conditioned freezing to tone, but not to context, in Fyntransgenic mice: relationship to NMDA receptor subunit $2 \mathrm{~B}$ function. Eur J Neurosci 21: 1359-1369.

Lasseter HC, Xie X, Ramirez DR, Fuchs RA (2010). Sub-region specific contribution of the ventral hippocampus to drug context-induced reinstatement of cocaine-seeking behavior in rats. Neuroscience 171: 830-839.

Lawrence DS, Niu J (1998). Protein kinase inhibitors: the tyrosinespecific protein kinases. Pharmacol Ther 77: 81-114.

Lee KY, Chou AK, Yang LC, Buerkle H (2003). NMDA receptors offer more than one functionality. Anesth Analg 96: 1533-1534.

Lu WY, Xiong ZG, Lei S, Orser BA, Dudek E, Browning MD et al (1999a). G-protein-coupled receptors act via protein kinase $\mathrm{C}$ and Src to regulate NMDA receptors. Nat Neurosci 2: 331-338.

Lu YF, Kojima N, Tomizawa K, Moriwaki A, Matsushita M, Obata $\mathrm{K}$ et al (1999b). Enhanced synaptic transmission and reduced threshold for LTP induction in fyn-transgenic mice. Eur $J$ Neurosci 11: 75-82.

Maldonado C, Rodriguez-Arias M, Castillo A, Aguilar MA, Minarro J (2007). Effect of memantine and CNQX in the acquisition, expression and reinstatement of cocaine-induced conditioned place preference. Prog Neuropsychopharmacol Biol Psychiatry 31: 932-939.

Matus-Amat P, Higgins EA, Sprunger D, Wright-Hardesty K, Rudy JW (2007). The role of dorsal hippocampus and basolateral amygdala NMDA receptors in the acquisition and retrieval of context and contextual fear memories. Behav Neurosci 121: 721-731.

Melik E, Babar E, Ozen E, Ozgunen T (2006). Hypofunction of the dorsal hippocampal NMDA receptors impairs retrieval of memory to partially presented foreground context in a singletrial fear conditioning in rats. Eur Neuropsychopharmacol 16: 241-247.

Nyiri G, Stephenson FA, Freund TF, Somogyi P (2003). Large variability in synaptic N-methyl-D-aspartate receptor density on interneurons and a comparison with pyramidal-cell spines in the rat hippocampus. Neuroscience 119: 347-363.

Pandis C, Sotiriou E, Kouvaras E, Asprodini E, Papatheodoropoulos C, Angelatou F (2006). Differential expression of NMDA and AMPA receptor subunits in rat dorsal and ventral hippocampus. Neuroscience 140: 163-175.

Paxinos G, Watson C (1997). The Rat Brain in Stereotaxic Coordinates. 2nd edn. Academic Press: San Diego.

Quinn JJ, Loya F, Ma QD, Fanselow MS (2005). Dorsal hippocampus NMDA receptors differentially mediate trace and contextual fear conditioning. Hippocampus 15: 665-674.

Rezayof A, Golhasani-Keshtan F, Haeri-Rohani A, Zarrindast MR (2007). Morphine-induced place preference: involvement of the central amygdala NMDA receptors. Brain Res 1133: 34-41.

Rodrigues SM, Schafe GE, LeDoux JE (2001). Intra-amygdala blockade of the NR2B subunit of the NMDA receptor disrupts the acquisition but not the expression of fear conditioning. J Neurosci 21: 6889-6896.

Sakurai S, Yu L, Tan SE (2007). Roles of hippocampal N-methyl-Daspartate receptors and calcium/calmodulin-dependent protein kinase II in amphetamine-produced conditioned place preference in rats. Behav Pharmacol 18: 497-506.

Salter MW (1998). Src, N-methyl-D-aspartate (NMDA) receptors, and synaptic plasticity. Biochem Pharmacol 56: 789-798.

Salter MW, Kalia LV (2004). Src kinases: a hub for NMDA receptor regulation. Nat Rev Neurosci 5: 317-328. 
Schafe GE, Stein PL, Park CR, Bernstein IL (1996). Taste aversion learning in fyn mutant mice. Behav Neurosci 110: 845-848.

Schumann J, Michaeli A, Yaka R (2009). Src-protein tyrosine kinases are required for cocaine-induced increase in the expression and function of the NMDA receptor in the ventral tegmental area. J Neurochem 108: 697-706.

Serrano A, Haddjeri N, Lacaille JC, Robitaille R (2006). GABAergic network activation of glial cells underlies hippocampal heterosynaptic depression. J Neurosci 26: 5370-5382.

Serrano A, Robitaille R, Lacaille JC (2008). Differential NMDAdependent activation of glial cells in mouse hippocampus. Glia 56: $1648-1663$.

Siegel SJ, Brose N, Janssen WG, Gasic GP, Jahn R, Heinemann SF et al (1994). Regional, cellular, and ultrastructural distribution of $\mathrm{N}$-methyl-D-aspartate receptor subunit 1 in monkey hippocampus. Proc Natl Acad Sci USA 91: 564-568.

Sinai L, Duffy S, Roder JC (2010). Src inhibition reduces NR2B surface expression and synaptic plasticity in the amygdala. Learn Mem 17: 364-371.

Stramiello M, Wagner JJ (2008). D1/5 receptor-mediated enhancement of LTP requires PKA, Src family kinases, and NR2Bcontaining NMDARs. Neuropharmacology 55: 871-877.

Szabadits E, Cserep C, Szonyi A, Fukazawa Y, Shigemoto R, Watanabe $M$ et al (2011). NMDA receptors in hippocampal GABAergic synapses and their role in nitric oxide signaling. J Neurosci 31: 5893-5904.

Takumi Y, Ramirez-Leon V, Laake P, Rinvik E, Ottersen OP (1999). Different modes of expression of AMPA and NMDA receptors in hippocampal synapses. Nat Neurosci 2: 618-624.
Todd KJ, Serrano A, Lacaille JC, Robitaille R (2006). Glial cells in synaptic plasticity. J Physiol Paris 99: 75-83.

Wang J, Carnicella S, Phamluong K, Jeanblanc J, Ronesi JA, Chaudhri $\mathrm{N}$ et al (2007). Ethanol induces long-term facilitation of NR2B-NMDA receptor activity in the dorsal striatum: implications for alcohol drinking behavior. J Neurosci 27: 3593-3602.

Wang J, Lanfranco MF, Gibb SL, Yowell QV, Carnicella S, Ron D (2010). Long-lasting adaptations of the NR2B-containing NMDA receptors in the dorsomedial striatum play a crucial role in alcohol consumption and relapse. J Neurosci 30: 10187-10198.

Xie X, Ramirez DR, Lasseter HC, Fuchs RA (2010). Effects of mGluR1 antagonism in the dorsal hippocampus on drug context-induced reinstatement of cocaine-seeking behavior in rats. Psychopharmacology 208: 1-11.

Xue JG, Masuoka T, Gong XD, Chen KS, Yanagawa Y, Law SK et al (2011). NMDA receptor activation enhances inhibitory GABAergic transmission onto hippocampal pyramidal neurons via presynaptic and postsynaptic mechanisms. J Neurophysiol 105: 2897-2906.

Yaka R, Tang KC, Camarini R, Janak PH, Ron D (2003). Fyn kinase and NR2B-containing NMDA receptors regulate acute ethanol sensitivity but not ethanol intake or conditioned reward. Alcohol Clin Exp Res 27: 1736-1742.

Yoshihara T, Ichitani Y (2004). Hippocampal N-methyl-Daspartate receptor-mediated encoding and retrieval processes in spatial working memory: delay-interposed radial maze performance in rats. Neuroscience 129: 1-10.

Supplementary Information accompanies the paper on the Neuropsychopharmacology website (http://www.nature.com/npp) 